\title{
The Coexistence of Nanostores within the Retail Landscape: A Spatial Statistical Study for Mexico City
}

\author{
Camilo Andrés Mora-Quiñones ${ }^{1}\left(\mathbb{D}\right.$, Leopoldo Eduardo Cárdenas-Barrón ${ }^{1, * \mathbb{D}}$, Josué C. Velázquez-Martínez ${ }^{2} \mathbb{D}$ \\ and Karla M. Gámez-Pérez ${ }^{1}$ (D) \\ 1 School of Engineering and Sciences, Tecnologico de Monterrey, Monterrey 64849, Mexico; camilomora@tec.mx \\ 2 Center for Transportation and Logistics, Massachusetts Institute of Technology, Cambridge, MA 02142, USA; \\ josuevm@mit.edu \\ * Correspondence: lecarden@tec.mx
}

\section{check for} updates

Citation: Mora-Quiñones, C.A.; Cárdenas-Barrón, L.E.; VelázquezMartínez, J.C.; Gámez-Pérez, K.M. The Coexistence of Nanostores within the Retail Landscape: A Spatial Statistical Study for Mexico City. Sustainability 2021, 13, 10615. https://doi.org/10.3390/ su131910615

Academic Editors: Riccardo Testa and Andrea Appolloni

Received: 21 July 2021

Accepted: 19 September 2021

Published: 24 September 2021

Publisher's Note: MDPI stays neutral with regard to jurisdictional claims in published maps and institutional affiliations.

Copyright: (c) 2021 by the authors. Licensee MDPI, Basel, Switzerland. This article is an open access article distributed under the terms and conditions of the Creative Commons Attribution (CC BY) license (https:/ / creativecommons.org/licenses/by/ $4.0 /)$.

\begin{abstract}
This paper aims to improve understanding of the grocery retail landscape in a megacity in the developing world. Over the past ten years (i.e., 2010-2020), retail in the grocery sector in Mexico City has changed significantly. The fast growth of chain convenience stores (CCS) and the financial stability of modern channel stores (MCS) has provoked speculation about whether nanostores (i.e., mom-and-pop stores) are going to disappear or if they will endure. In developing countries nanostores dominate the grocery retail market, providing a source of income to millions of families. While some studies suggest that nanostores will keep growing in number because they are more likely to be attached to growing middle- and low-income consumers in developing countries, our results show that high- and medium-high-income consumers purchase at nanostores too. Through a comprehensive spatial statistical analysis, we provide evidence that nanostores will endure and, most importantly, coexist with MCS and CCS regardless of the socioeconomic levels that coexist in the urban areas of a developing megacity. To gain a thorough understanding of how the grocery retail market is organized in Mexico City, and provide a richer discussion on the logistics and managerial implications for stakeholders (e.g., customers, practitioners, shopkeepers, suppliers, and policymakers), we also validate hypotheses from the literature related to this context and the three channels studied in this work.
\end{abstract}

Keywords: grocery retail; nanostores; retail modernization; developing counties; fragmentation; supply chain; social impact

\section{Introduction}

In developing countries, megacities shape a unique urban environment, establishing the conditions conducive to the presence of thousands of differently formatted grocery retail (GR) stores. In Mexico City, these stores cover almost every corner of the megacity, offering groceries and everyday items to inhabitants of various socioeconomic levels.

These grocery stores compete fiercely and do not cooperate. Therefore, the objective of this work is twofold. First, to conduct a comprehensive study about the GR landscape for Mexico City to better understand the presence of different types of stores in urban areas where inhabitants of various socioeconomic levels cohabit. Second, to investigate whether nanostores will disappear or endure, given that modern channel stores and chain convenience stores have penetrated territories where nanostores used to dominate.

Mexican consumers have diverse reasons for preferring different store formats; either modern channel stores (MCS) like Walmart, chain convenience stores (CCS) such as 7 Eleven or OXXO, or traditional stores-also known as nanostores.

During the past decade (i.e., 2001-2020), the GR sector in Mexico City changed considerably. The fast growth in openings of CCS and MCS has provoked speculation about the impact that it is having on nanostores' business. For instance, local journals' headlines 
suggest that "The corner stores could disappear" (El Financiero [1]), and others have even claimed that in Mexico City, between 10 and 15 nanostores die when a new CCS is opened nearby (El Sol de México [2]). More recent news posts mention that nanostores are at risk of disappearing due to the supremacy of supermarkets (Forbes [3]).

Accordingly, our paper contributes to the extant literature by providing evidence that not only the middle- and low-income consumers in developing megacities are attached to nanostores, but high- and medium-high income consumers too. Thus, the main finding of this study is that nanostores, MCS, and CCS coexist under the conditions of a megacity in the developing world like Mexico City, regardless of the socioeconomic levels of those that cohabit urban areas.

In Mexico City, the GR landscape comprises approximately 90,000 stores, of which nanostores represent roughly $97 \%$. The rest of the stores are MCS and CCS, with approximately 500 and 2000 stores, respectively. These GR channels have adapted their stores and assortments (Alibeiki and Vaidyanathan [4]) to the requirements of consumers, expanding to penetrate areas of the city where they do not have a presence.

The MCS are grocery retailers that rely on high volumes and quick stock turnover to reach the economies of scale, like supermarkets and wholesalers. The CCS are small, but modern, retail businesses that stock a range of everyday items such as groceries, snack foods, candy, toiletries, soft drinks, tobacco products, magazines, and newspapers (Hervert-Escobar et al. [5]). Nanostores are traditional grocery retail stores, also known as mom-and-pop stores. In general, these businesses are family-operated, independent, and non-organized, mostly with less than $100 \mathrm{~m}^{2}$ commercial space (Fransoo et al. [6]).

The term "nanostores" was introduced by Blanco and Fransoo [7]. Their work refers to the traditional retail channel as nanostores to make abundantly clear that these traditional stores are very different from supermarkets, chain convenience stores, or hypermarkets in terms of size, distribution, sales processes, and operations. Consequently, scholarly interest in the grocery retail sectors in developing and emerging markets has spiked (see Table 1).

Furthermore, in emerging markets like Mexico City, the socio-demographic differentiation presents an urban environment very different from cities in developed countries. Nanostores are located handily within residential neighborhoods, providing convenience for daily shopping. Nanostores cover the vast majority of Mexico City, including urban, suburban, and rural areas, as shown in Figure 1.

In this context, nanostores offer unique value to the local economy. They are the source of income for thousands of families. In Mexico City alone, nanostores account for $84 \%$ of the GR sector employment ( 440 thousand direct employments), while MCS and CCS account for $12 \%$ and $4 \%$, respectively.

The nanostore channel is the most preferred channel to purchase groceries for customers that cannot afford to buy in a hypermarket or supermarket. Moreover, nanostores facilitate informal credit to their consumers. As a result, consumers' purchasing loyalty to the channel remains high.

However, the high fragmentation of this market causes significant inefficiencies in the distribution of goods, particularly for nanostores that have limited cash and storage space, meaning small drop sizes and frequent visits by suppliers. Consequently, consumer packaged goods (CPG) companies charge higher prices to nanostores, making over $10 \%$ more profit by selling directly to them than to MCS (Ge et al. [8]). In addition, nanostore shopkeepers often charge slightly higher prices than CCS and MCS, which in some cases can be as high as 30\% (Fransoo et al. [6]). These conditions imply that consumers pay higher prices when buying from nanostores, thereby affecting the economies of the poorest.

Furthermore, during the past two decades, several studies have been conducted to understand the evolution of the grocery retail sector, mostly in developing countries (see Table 1), and the impact that the MCS is having on nanostores. These works highlight the importance of this matter and identify the factors that lead traditional stores to endure despite the fast growth of modern retail. 
Table 1. Studies that have been conducted to understand the grocery retail sector (2001-2021).

\begin{tabular}{|c|c|c|c|}
\hline Author(s) & Study & Country & Sample Size and Type \\
\hline Farhangmehr et al. [9] & $\begin{array}{l}\text { Hypermarkets vs. traditional } \\
\text { retail stores: consumers' and retailers' } \\
\text { perspectives in Braga: a case study }\end{array}$ & Portugal & $\begin{array}{l}\text { Interviews (50 respondents) } \\
\text { Focus groups }(4)\end{array}$ \\
\hline $\begin{array}{l}\text { Goldman, A., \& } \\
\text { Hino, H. [10] }\end{array}$ & $\begin{array}{l}\text { Supermarkets vs. traditional retail stores: } \\
\text { diagnosing the barriers to } \\
\text { supermarkets' market share growth in an } \\
\text { ethnic minority community }\end{array}$ & Israel & Survey (511 respondents) \\
\hline D'Andrea et al. [11] & $\begin{array}{l}\text { Why small retailers endure in } \\
\text { Latin America }\end{array}$ & Argentina & $\begin{array}{c}\text { Focus group (208 participants) } \\
\text { Store checks (217) } \\
\text { Interviews (190) }\end{array}$ \\
\hline Coen et al. [12] & $\begin{array}{l}\text { "Without tiendas it's a dead } \\
\text { neighborhood": The socio-economic } \\
\text { importance of small trade stores in } \\
\text { Cochabamba, Bolivia }\end{array}$ & Bolivia & Interviews (60 respondents) \\
\hline $\begin{array}{c}\text { Lenartowicz, T., \& } \\
\text { Balasubramanian, S. [13] }\end{array}$ & $\begin{array}{l}\text { Practices and performance of small retail } \\
\text { stores in developing economies }\end{array}$ & Brazil & Interviews (51 respondents) \\
\hline Paswan et al. [14] & $\begin{array}{l}\text { Small versus large retail stores in an } \\
\text { emerging market-Mexico }\end{array}$ & Mexico & Survey (981 respondents) \\
\hline $\begin{array}{c}\text { Amine, A., \& } \\
\text { Lazzaoui, N. [15] }\end{array}$ & $\begin{array}{l}\text { Shoppers' reactions to modern food } \\
\text { retailing systems in an emerging country: } \\
\text { the case of Morocco }\end{array}$ & Morocco & $\begin{array}{c}\text { Behavioral, in-store, } \\
\text { observations }(17 \mathrm{~h}) \\
\text { Interviews (16 respondents) }\end{array}$ \\
\hline $\begin{array}{l}\text { Narayan, V., Rao, V. R., } \\
\quad \text { \& Sudhir, K. [16] }\end{array}$ & $\begin{array}{l}\text { Early adoption of modern grocery retail } \\
\text { in an emerging market: evidence } \\
\text { from India }\end{array}$ & India & Panel data (270 observations) \\
\hline $\begin{array}{l}\text { Boulaksil, M. \& } \\
\text { Belkora, J. [17] }\end{array}$ & $\begin{array}{c}\text { Distribution strategies toward nanostores } \\
\text { in emerging } \\
\text { markets: the Valencia case }\end{array}$ & Morocco & Case study \\
\hline Boulaksil et al. [18] & $\begin{array}{l}\text { Understanding the fragmented demand } \\
\text { for transportation: small } \\
\text { traditional retailers in emerging markets }\end{array}$ & Morocco & Survey (333 respondents) \\
\hline Escamilla, R. et al. [19] & $\begin{array}{l}\text { Improving agility, adaptability, } \\
\text { alignment, accessibility, and affordability } \\
\text { in nanostore supply chains }\end{array}$ & $\begin{array}{l}\text { Developing and } \\
\text { emerging markets }\end{array}$ & Review paper \\
\hline
\end{tabular}

As presented in Table 1, most of these studies rely on interviews, surveys, or focus groups that study a sample of the population. Instead, we used the entire population of nanostores, MCS, and CCS in Mexico City, to acquire more information and reduce the potential for error in our results. We retrieved official data from the total number of registered stores in the city. The latter means that we used the data of all the existing nanostores, MCS, and CCS formally established in the city. We retrieved more than three million records for Mexico City, including the number of stores per channel per Zip Code, business names, employee numbers, populations per socioeconomic level (SEL), and geolocations, among others.

Previous studies have focused on understanding how the modern channel can enter areas where nanostores dominate. For example, Farhangmehr et al. [9] studied the impact of modern channel stores' market penetration on traditional stores and customers. Similarly, Goldman and Hino [10] investigated the barriers to entry faced by MCS when trying to penetrate areas where nanostores dominate. For Mexico, Paswan et al. [14] conducted an empirical study to investigate consumers' preferences for MCS or nanostores. 


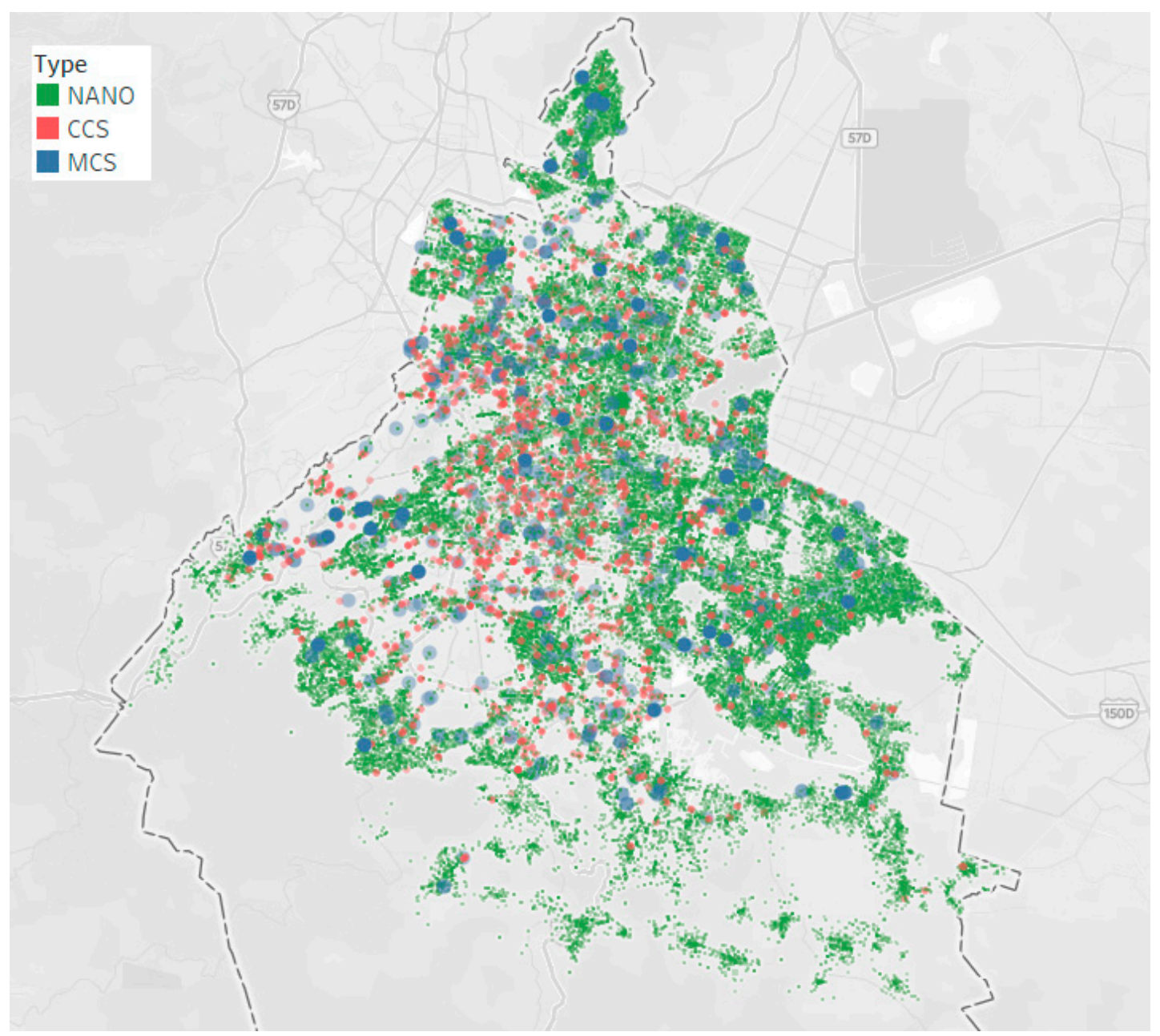

Figure 1. Cumulative openings of MCS, CCS, and nanostores in Mexico City (2010-2020).

Other researchers have conducted studies to determine why nanostores endure, and the value they add to their communities. For example, D'Andrea et al. [11] evidenced how nanostores fit the needs of emerging consumers, and Coen et al. [12] highlighted the value that nanostores add to the community. In more recent research, Boulaksil et al. [18] presented a cluster analysis to better understand the fragmented business environment of nanostores and their order behavior, which has a significant impact on business decisions upstream in the supply chain. In addition, Escamilla et al. [19] presented findings suggesting that urban and rural nanostores can become competitive by increasing their supply chain capabilities; specifically, business agility, adaptability, and alignment.

However, the configuration of the grocery retail sector, in a developing market where inhabitants of different socioeconomic levels cohabit, is still unclear. Therefore, we conducted this research to contribute to the literature by illustrating the configuration of the grocery retail landscape in the developing market megacity of Mexico City, where customers from various socioeconomic levels cohabit.

In addition, from the literature presented in Table 1, we identified several statements, findings, and insights about the conditions of nanostores in other developing markets. We consider that those contentions are not conclusive for the developing world because each city presents different settings in terms of urbanization, socioeconomic mix, and purchasing power, among other factors. However, by studying these factors we can obtain a deeper understanding of how the grocery retail landscape in Mexico City is structured. Hence, the purpose of presenting these statements as hypotheses, and testing them, is to structure our investigations into why nanostores endure in Mexico City despite the penetration 
of supermarkets, hypermarkets, and convenience stores in areas where nanostores were, previously, the only channel present.

These statements describe the conditions of the grocery retail sector in other urban areas. For instance, some studies suggest that MCS and CCS target high- and middlehigh-income groups. Other studies suggest that inhabitants of low- and middle-lowsocioeconomic levels are the ones that prefer purchasing their daily goods from nanostores, mainly because of their proximity and adaptability to the needs of these types of consumers. By testing these hypotheses, we aim to gain a thorough understanding of the market conditions in Mexico City.

Hypothesis 1 (H1). "The upper and middle classes are more likely to welcome new sale formats (modern retailing)". Amine and Lazzaoui [15].

In Mexico City, new store formats of MCS are penetrating areas where nanostores used to dominate, causing speculation about their impact on nanostores. Therefore, by testing $\mathrm{H} 1$ we aim to understand whether the expansion of MCS is more likely to happen in upper- and middle-income areas or in low and middle-low-income areas.

Hypothesis 2 (H2). "Large segments of the population in developing countries-mostly the lowand lower-middle class_remain attached to nanostores in their neighborhood". Boulaksil et al. [18].

We have observed that nanostores are present in low- and lower-middle-income areas and high socioeconomic level areas. Therefore, by testing $\mathrm{H} 2$ we investigate how the mix of socioeconomic levels influences the number of nanostores in Mexico City.

Hypothesis 3 (H3). "Location is a compelling proposition of small retailers to emerging consumers, many of who overwhelmingly make small daily purchases. The physical proximity of stores to where they live and/or work, translates into significantly lower "total purchasing cost"". D'Andrea et al. [11].

By testing this hypothesis, we quantify the proximity differences among the three channels in Mexico City.

Hypothesis 4 (H4). "However, the pricing in the modern convenience channel is usually targeted at the middle-class consumers, and only competes to a limited extent with the traditional channel". Blanco and Fransoo [7].

The fast growth of CCS has generated much speculation about the negative impact that it has on nanostores. Through testing this hypothesis, we investigate whether the CCS are focused on the middle-income groups in terms of the number of existing stores in areas of different socioeconomic levels.

Hypothesis 5 (H5). "In fact, the evidence shows that smaller scale retailers fit the needs of emerging consumers quite well". D'Andrea et al. [11].

We hypothesize that nanostores not only fit the needs of emerging consumers, but of consumers across all socioeconomic levels.

Hypothesis 6 (H6). "One viewpoint is that modern retail will be initially embraced by the rich upper middle class, and the lower classes will follow". Narayan et al. [16].

By testing H6, we investigate the presence of MCS across areas with different socioeconomic levels to determine if this channel is more present in the wealthiest areas. 
Hypothesis 7 (H7). "The dominance of small retailers in São Paulo is striking. However, large supermarkets and other stores with more sophisticated management (e.g., gas stations owned by multinational petrochemical firms) coexist with the small retail sector". Lenartowicz and Balasubramanian [13].

This statement suggests the coexistence of different GR channels in a developing market. By testing this hypothesis we aim to understand the configuration of the GR sector in Mexico City, in terms of the MCS, CCS, and nanostores present in a determined area.

As described, none of the previous studies address our research question, that is: RQ1. How is the grocery retail landscape configured in a developing market megacity where customers from various socioeconomic levels cohabit?

We argue that despite the inefficiencies of nanostores, they will endure and coexist with other channels because, in the developing world, urban areas have a mix of socioeconomic levels that set up the conditions for a more diverse market. Therefore, the following hypothesis is forwarded:

Hypothesis 8 (H8). Nanostores, MCS, and CCS coexist under the conditions of a megacity in a developing country like Mexico City regardless of the socioeconomic levels of the consumers that cohabit urban areas.

The rest of the paper is organized as follows. In the next section, we describe the methodology. Section 3 presents the results. Section 4 discusses managerial implications, and Section 5 presents our conclusions and recommendations for further research.

\section{Methodology}

The procedure we followed to perform this study included the following steps: (a) conducting a literature review to identify relevant hypotheses from previous studies and findings associated with the GR landscape, (b) secondary data collection from official sources, (c) cleansing of data to perform statistical analyses, and (d) obtaining findings and insights for practitioners.

We examined the GR landscape through spatial and statistical analyses, such as pairwise comparisons for one-way analysis of variance (ANOVA), interaction plots, and interval plots. We obtained official data from the Mexican national statistical directory of economic units (DENUE for its abbreviation in Spanish) to obtain the number of nanostores, chain convenience stores (CCS), and modern channel stores (MCS) opening in Mexico City's municipalities over time. The DENUE belongs to the Mexican Institute of geography and statistics (INEGI for its abbreviation in Spanish). It contains a classification of businesses by sector, economic activity, size (i.e., number of employees), and location, among other characteristics. For this study, we used the economic activities that correspond to small grocery stores (nanostores), self-service stores (CCS), and large grocery stores (MCS); 46,111, 46,211, and 43,111, respectively.

Additionally, more data were retrieved from (INEGI), like the social development index per Zip Code in Mexico City (2010), the national income and expenditure survey (ENIGH, for its acronym in Spanish) from 2016, and the economic census of 2014. Afterwards, data cleansing was performed to create several datasets, enabling us to conduct spatial analyses to facilitate the illustration of geolocation data with respect to different types of stores within the city, as depicted in Figure 1. Furthermore, after merging several databases, it was possible to illustrate the coexistence of MCS, CCS, and nanostores regardless of the SEL, as presented in Figure 2.

Subsequently, we created a dataset to conduct statistical analyses capable of assessing the positions put forward in previous literature, and which could shed light on the factors that foster the survival of nanostores. Table 2 provides information regarding the variables that we used to conduct the analyses. As shown in Table 2, the factors that we considered, to address the research question, are related to socioeconomic group populations, store 
density, and store presence. We did not consider other moderating or mediating variables, as they are beyond the scope of our research.

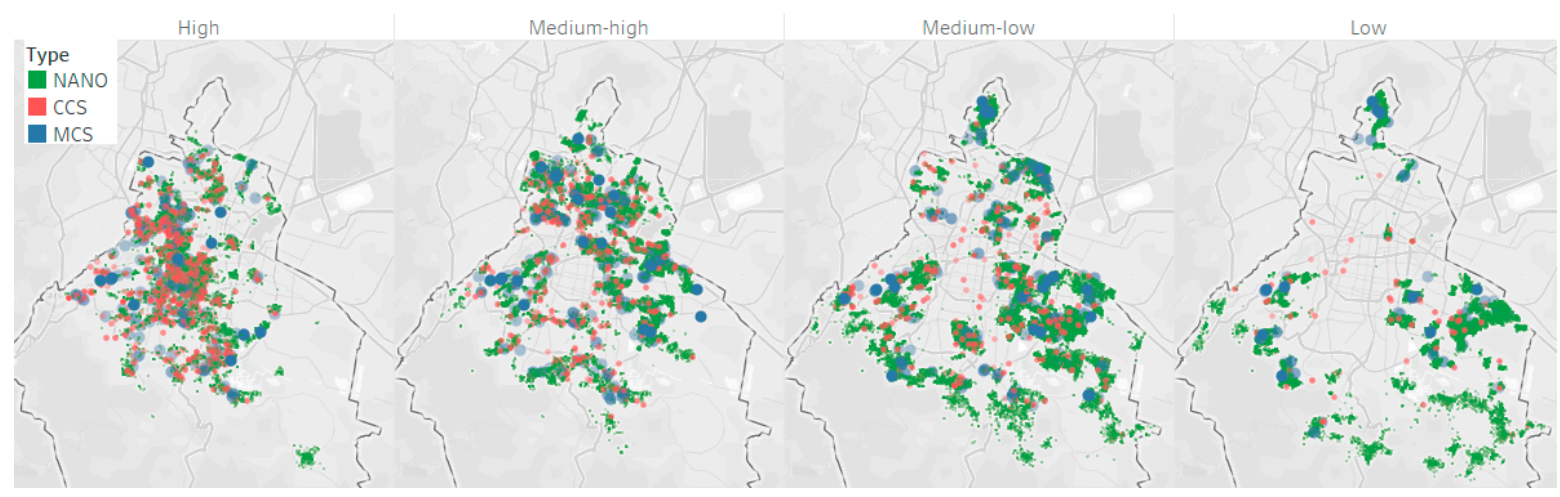

Figure 2. Cumulative openings of MCS, CCS, and nanostores in Mexico City per SEL (2010-2019).

Table 2. Dependent and Independent variables and descriptions.

\begin{tabular}{|c|c|c|}
\hline Group & Variable & Description \\
\hline \multirow{4}{*}{ Population per SEL } & Pop. $\mathrm{H}$ & Discrete variable. Number of High SEL inhabitants per Zip Code \\
\hline & Pop. $\mathrm{MH}$ & Discrete variable. Number of Medium-high SEL inhabitants per Zip Code \\
\hline & Pop. ML & Discrete variable. Number of Medium-low SEL inhabitants per Zip Code \\
\hline & Pop. L & Discrete variable. Number of High SEL inhabitants per Zip Code \\
\hline \multirow{4}{*}{ Ratios of CCS per SEL } & R. CCS/Pop. H & Continuous variable. Ratio between CCS and Pop. High \\
\hline & R. CCS/Pop. MH & Continuous variable. Ratio between CCS and Pop. Medium-high \\
\hline & R. CCS/Pop. ML & Continuous variable. Ratio between CCS and Pop. Medium-low \\
\hline & R. CCS/Pop. L & Continuous variable. Ratio between CCS and Pop. Low \\
\hline \multirow{4}{*}{ Ratios of MCS per SEL } & R. MCS/Pop. H & Continuous variable. Ratio between MCS and Pop. High \\
\hline & R. MCS/Pop. MH & Continuous variable. Ratio between MCS and Pop. Medium-high \\
\hline & R. MCS/Pop. ML & Continuous variable. Ratio between MCS and Pop. Medium-low \\
\hline & R. MCS/Pop. L & Continuous variable. Ratio between MCS and Pop. Low \\
\hline \multirow{4}{*}{ Ratios of nanostores per SEL } & R. NANO/Pop. H & Continuous variable. Ratio between NANO and Pop. High \\
\hline & R. NANO/Pop. MH & Continuous variable. Ratio between NANO and Pop. Medium-high \\
\hline & R. NANO/Pop. ML & Continuous variable. Ratio between NANO and Pop. Medium-low \\
\hline & R. NANO/Pop. L & Continuous variable. Ratio between NANO and Pop. Low \\
\hline \multirow{3}{*}{$\begin{array}{l}\text { Ratio of the number of } \\
\text { stores per square kilometer }\end{array}$} & R. CCS/Area & Continuous variable. Ratio between CCS and Area $\left(\mathrm{km}^{2}\right)$ \\
\hline & R. MCS/Area & Continuous variable. Ratio between MCS and Area $\left(\mathrm{km}^{2}\right)$ \\
\hline & R. NANO/Area & Continuous variable. Ratio between NANO and Area $\left(\mathrm{km}^{2}\right)$ \\
\hline \multirow{4}{*}{$\begin{array}{l}\text { Binary variable to show the } \\
\text { presence or not of a SEL }\end{array}$} & Bin. $\mathrm{H}$ & $\begin{array}{l}\text { Binary variable. Nominal scale (two categories): "Presence of High SEL } \\
\text { population" = } 1 \text { to "No presence of High SEL population" = }\end{array}$ \\
\hline & Bin. $\mathrm{MH}$ & $\begin{array}{c}\text { Binary variable. Nominal scale (two categories): "Presence of } \\
\text { Medium-high SEL population" }=1 \text { to "No presence of Medium-high SEL } \\
\text { population" }=0\end{array}$ \\
\hline & Bin. ML & $\begin{array}{c}\text { Binary variable. Nominal scale (two categories): "Presence of } \\
\text { Medium-low SEL population" }=1 \text { to "No presence of Medium-low SEL } \\
\text { population" }=0\end{array}$ \\
\hline & Bin. L & $\begin{array}{l}\text { Binary variable. Nominal scale (two categories): "Presence of Low SEL } \\
\text { population" }=1 \text { to "No presence of Low SEL population" }=0\end{array}$ \\
\hline
\end{tabular}


Mexico City is divided into 1000 zip codes. Our dataset consists of all the Zip Codes of Mexico City. However, some of the Zip Codes were removed due to a lack of inhabitants (e.g., airports, parks, restricted areas), and the need to maintain a homogeneous sample size of 906 usable observations (i.e., $\sim 90 \%$ of the universe). Thus, our large size aided us in providing robust evidence about our results. The latter led to a better discussion of our insights and managerial implications (Goswami et al. [20]), providing more value to the stakeholders of the GR sector of Mexico City.

\section{Results and Discussion}

In this section, we present the results of our statistical analyses. The level of significance was set at $0.05(\alpha=0.05)$. Thus, with a $95 \%$ confidence interval for the means of each group, where if the $p$-value $\leq \alpha$, then we reject the null hypothesis. However, if the $p$-value $>\alpha$, then we fail to reject the null hypothesis. Accordingly, we list the hypotheses identified from the literature, and state the null and alternative hypotheses for each based on our research variables (See Table 2) as follows.

Hypothesis 1 (H1). The upper-and middle-income groups are more likely to welcome new sale formats (modern retailing). Amine and Lazzaoui [15].

Null: $\mu$ (R. MCS/Pop. H $)=\mu($ R. MCS/Pop. MH $)=\mu($ R. MCS $/$ Pop. $M H)=\mu($ R. MCS/Pop. L)

Alternative: $\mu$ (R. MCS/Pop. H) $\neq \mu$ (R. MCS/Pop. MH) $\neq \mu($ R. MCS $/$ Pop. MH $) \neq$ $\mu$ (R. MCS/Pop. L)

Hypothesis 2 (H2). Large segments of the population in developing countries, mostly the lowand lower-middle-income groups, remain attached to nanostores in their neighborhood. Boulaksil et al. [18].

Null: $\mu$ (R. NANO/Pop. H $)=\mu($ R. NANO $/$ Pop. MH $)=\mu($ R. NANO $/$ Pop. ML $)=\mu($ R. NANO/Pop. L)

Alternative: $\mu$ (R. NANO/Pop. H) $\neq \mu$ (R. NANO/Pop. MH) $\neq \mu($ R. NANO/Pop. ML) $\neq \mu($ R. NANO/Pop. L $)$

Hypothesis 3 (H3). Location is a compelling proposition of small retailers to emerging consumers, many of who overwhelmingly make small daily purchases. The physical proximity of stores to where they live and/or work, translates into significantly lower "total purchasing cost". D'Andrea et al. [11].

Null: $\mu($ NANO $/$ Area $)=\mu($ MCS $/$ Area $)=\mu($ CCS $/$ Area $)$

Alternative: $\mu$ (NANO/Area $\neq \mu(\mathrm{MCS} /$ Area $) \neq \mu(\mathrm{CCS} /$ Area $)$

Hypothesis 4 (H4). However, the pricing in the modern convenience channel is usually targeted at the middle-income consumers, and only competes to a limited extent with the traditional channel. Blanco and Fransoo [7].

Null: $\mu($ R. CCS $/$ Pop. H $)=\mu($ R. CCS $/$ Pop. $M H)=\mu($ R. CCS $/$ Pop. $M H)=\mu($ R. CCS/Pop. L)

Alternative: $\mu$ (R. CCS $/$ Pop. H $) \neq \mu($ R. CCS $/$ Pop. MH $) \neq \mu($ R. CCS $/$ Pop. MH $) \neq \mu($ R. CCS/Pop. L)

Hypothesis 5 (H5). In fact, the evidence shows that smaller scale retailers fit the needs of emerging consumers quite well. D'Andrea et al. [11].

Null: $\mu$ (R. NANO/Pop. H $)=\mu($ R. NANO $/$ Pop. MH $)=\mu($ R. NANO $/$ Pop. ML $)=\mu($ R. NANO/Pop. L) 
Alternative: $\mu$ (R. NANO/Pop. H) $\neq \mu$ (R. NANO/Pop. MH) $\neq \mu$ (R. NANO/Pop. $\mathrm{ML}) \neq \mu($ R. NANO $/$ Pop. $\mathrm{L})$

Hypothesis 6 (H6). One viewpoint is that modern retail will be initially embraced by the rich upper-middle income groups, and that the lower income groups will follow. Narayan et al. [16].

Null: $\mu$ (R. MCS/Pop. H $)=\mu($ R. MCS/Pop. MH $)=\mu($ R. MCS/Pop. MH $)=\mu($ R. MCS/Pop. L)

Alternative: $\mu$ (R. MCS/Pop. H $\neq \neq($ R. MCS $/$ Pop. MH $) \neq \mu($ R. MCS $/$ Pop. MH $) \neq$ $\mu$ (R. MCS/Pop. L)

Hypothesis 7 (H7). The dominance of small retailers in São Paulo is striking. However, large supermarkets and other stores with more sophisticated management (e.g., gas stations owned by multinational petrochemical firms) coexist with the small retail sector. Lenartowicz and Balasubramanian [13].

Null: $\mu($ R. NANO/Pop. H $)=\mu($ R. NANO/Pop. MH $)=\mu($ R. NANO $/$ Pop. ML $)=\mu($ R. NANO/Pop. L)

Alternative: $\mu$ (R. NANO/Pop. H) $\neq \mu$ (R. NANO/Pop. MH) $\neq \mu($ R. NANO/Pop. $\mathrm{ML}) \neq \mu($ R. NANO/Pop. L $)$

Hypothesis 8 (H8). Nanostores, MCS, and CCS coexist under the conditions of a megacity in a developing country like Mexico City regardless of the socioeconomic levels that cohabit urban areas.

Null: $\mu$ (R. NANO/Pop. H $)=\mu($ R. NANO $/$ Pop. MH $)=\mu($ R. NANO $/$ Pop. ML $)=\mu($ R. NANO/Pop. L)

Alternative: $\mu$ (R. NANO/Pop. H $) \neq \mu($ R. NANO/Pop. MH $) \neq \mu($ R. NANO/Pop. ML) $\neq \mu($ R. NANO/Pop. L $)$

First, we tested hypotheses 1 and $6(\mathrm{H} 1, \mathrm{H} 6)$. H1 proposes that the high and mediumhigh populations are more likely to welcome MCS, while H6 suggests that the high and medium-high SEL will initially accept MCS and that the lower SEL will then follow.

We tested both hypotheses using a one-way ANOVA to determine whether the difference in means was statistically significant. We also present an Interval Plot to compare the confidence intervals of the groups' means (ratio between MCS and each SEL) with a 95\% confidence interval for the means of each group as presented in Figure 3.

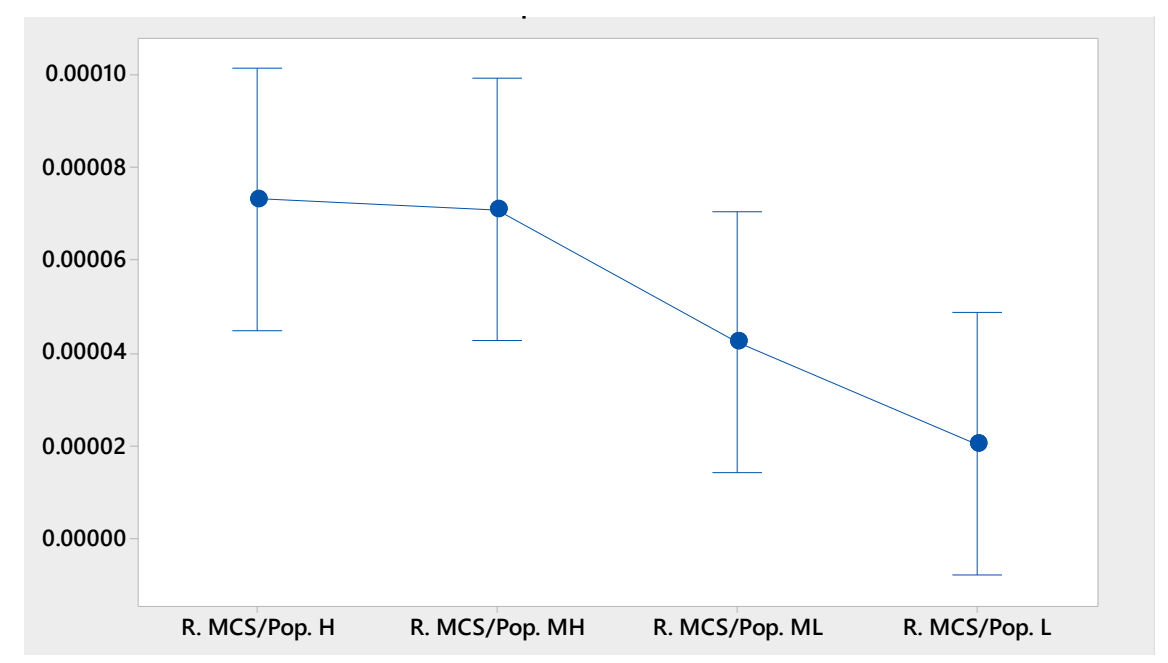

Figure 3. Interval Plot for MCS per SEL. 
As the intervals for the means of Pop. H, Pop. MH, Pop. ML, and Pop. L overlap, the population means may be statistically significant, suggesting no statistical difference for the penetration of MCS in high, medium-high-, medium-low-, and low- income groups.

Nonetheless, the interval plot suggests that the confidence intervals of the high- and medium-high-income groups' means are greater than the medium-low- and low-income groups' means, implying that MCS are more likely to be accepted by high- and mediumhigh SEL, followed by lower SEL; thus, H6 may hold for Mexico City.

This result means that the modern channel stores are more targeted to consumers with more purchasing power for buy-to-stock goods, and those with the means of transportation to visit these stores and make payment via methods other than cash. Nevertheless, the results also show no statistical difference between the mean numbers of MCS present across different socioeconomic areas. The latter implies that MCS have a significant presence across all the SELs in Mexico City.

Moreover, this result implies that MCS should understand consumers' shopping behaviors in low and medium-low SEL areas if they are to adapt their shopping experiences and assortment policies, as suggested by Amine and Lazzaoui [15]. The latter is vital to defining a positioning strategy that increases attractiveness in areas where nanostores dominate.

The previous procedure was repeated for nanostores (see Figure 4) to test hypotheses 2 and $5(\mathrm{H} 2, \mathrm{H} 5)$. $\mathrm{H} 2$ indicates that medium-low and low SEL remain attached to nanostores in their neighborhood, and $\mathrm{H} 5$ states that nanostores fit the needs of these SELs. In this test, there was no statistically significant difference with respect to the existence of nanostores regardless of the population per SEL, suggesting that consumers will choose a store type because it meets their functional needs (Paswan et al. [14]) regardless of their SEL.

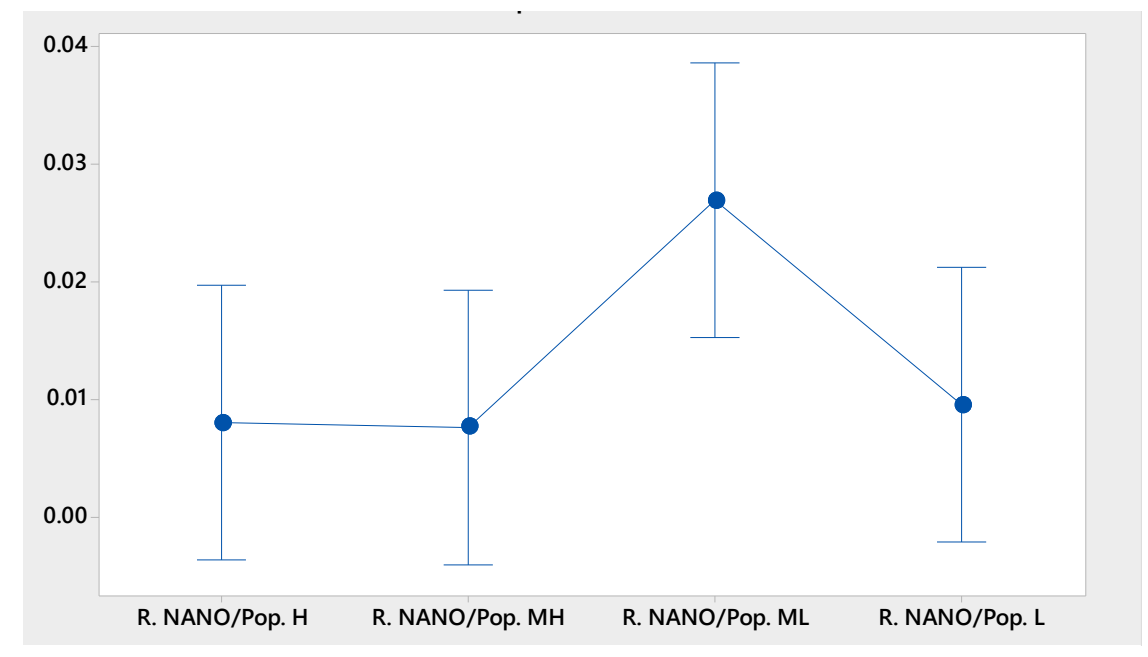

Figure 4. Interval Plot for nanostores per SEL.

To elaborate, nanostores usually offer commodities such as milk, bread, eggs, beer, or tobacco. Therefore, regardless of the socioeconomic level, those goods meet customers' needs across all SELs. For example, the products of the most significant CPGs can be found in any channel, implying that-if the need for goods is buy-to-consume-consumers will select the channel in closest proximity, and with the product on-shelf (i.e., available now and displayed for sale).

The results we obtained differed from previous studies that suggested nanostores are more likely to serve impoverished urban areas (D'Andrea et al. [11]; Paswan et al. [14]). The unplanned integration and proximity between low-, medium-, and high-income areas could explain why nanostores are present across these SEL areas. Furthermore, we used an interaction plot to show the relationship between each one of these categorical factors (Bin. $\mathrm{H}$, Bin, $\mathrm{MH}$, Bin.ML, Bin.L) and a continuous response (NANO), and their dependence on the value of a second categorical factor (Bin. H, Bin, MH, Bin.ML, Bin.L) as shown in 
Figure 5. It is worth mentioning that, in Mexico City, it is common to find two or three SELs cohabiting in the same Zip Code.

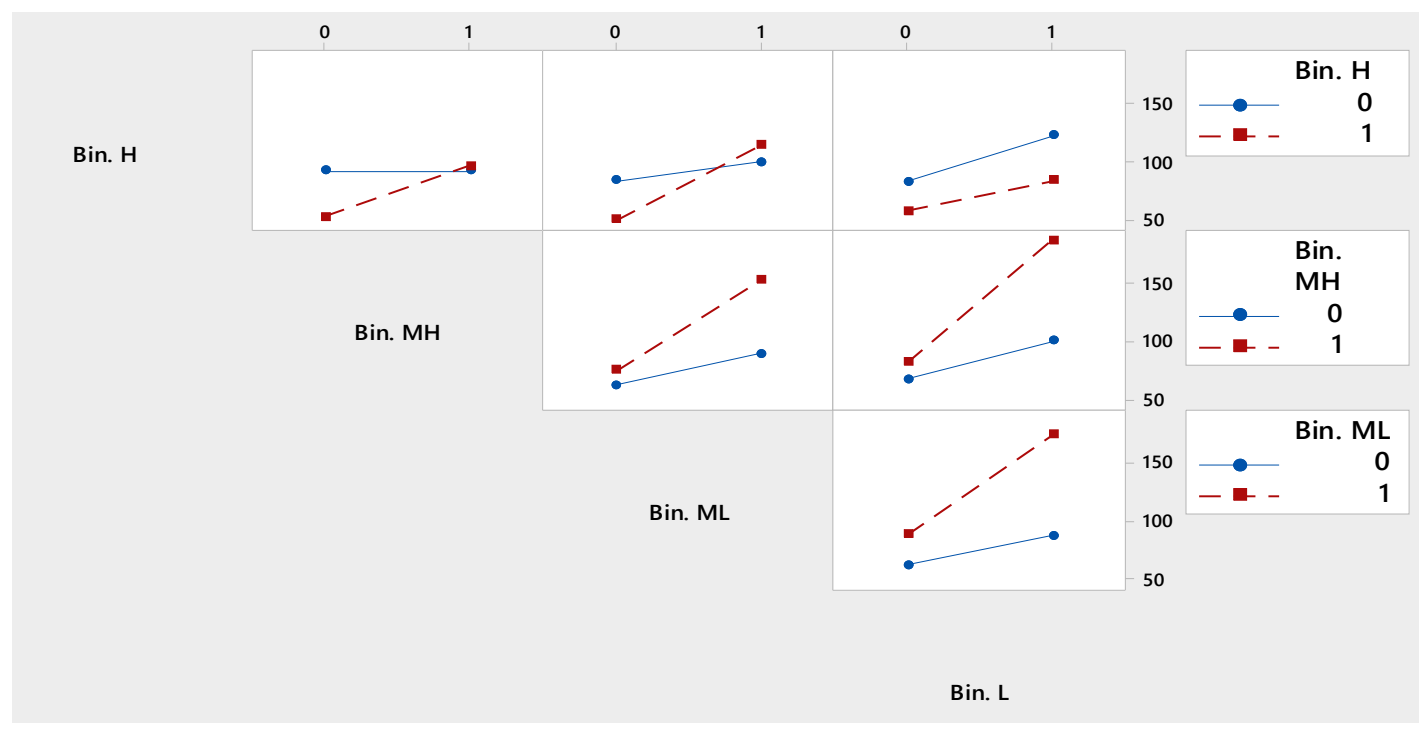

Figure 5. Interaction Plot for Nanostores in the presence of populations of each socioeconomic level.

For this reason, we decided to use an interaction plot to display the means for the levels of one factor on the x-axis, and a separate line for each level of another factor. In all the cases, the mean of nanostores was above 50, implying that, despite the social outline of an area, nanostores will have a presence. Moreover, the mean number of nanostores increases significantly in medium-high, medium-low, and low populations due to a strong interaction. By contrast, mean numbers remain stable in the presence of high SEL populations. Thus, $\mathrm{H} 2$ holds for the conditions of Mexico City.

For testing hypothesis $3(\mathrm{H} 3)$, which states that the physical proximity of nanostores is a compelling proposition to facilitate the frequency of purchases, we estimated proximity by obtaining a continuous measure of the density of stores per area by calculating the ratio count for each type of GR store to the area of each Zip Code.

We used Tukey's multiple comparison test to determine which means, among a set of ratio means, differed from the rest. First, we conducted a one-way ANOVA to evaluate whether there was any evidence to indicate that differences in the population means. As shown in Table 3, the mean of NANO/Area (202) differed significantly from the CCS/Area (3.2) and MCS/Area (0.8) means.

Table 3. Store per area ratios by group, using the Tukey method and a $95 \%$ confidence interval.

\begin{tabular}{ccccc}
\hline Factor & N & Mean & Grouping \\
\hline R. NANO/Area & 906 & 202 & & \\
R. CCS/Area & 906 & 3.229 & & $\mathrm{~B}$ \\
R. MCS/Area & 906 & 0.828 & $\mathrm{~B}$ \\
\hline
\end{tabular}

Therefore, as shown in Figure 6, the physical proximity of nanostores is significantly greater than the proximity of MCS or CCS to the households, implying that this condition is one of the factors facilitating the frequency of nanostore visits; a key factor responsible for their endurance despite the fast growth of modern retail.

This finding is consistent with previous studies conducted in other developing countries such as Morocco (Boulaksil et al. [18]), Bolivia (Coen et al. [12]), and Argentina (D'Andrea et al. [11]). Thus, in the developing world, the grocery retail market is highly 
fragmented. The latter implies many challenges in the distribution of goods, where van sales agents can serve more than 60 nanostores per route (Fransoo et al. [6]).

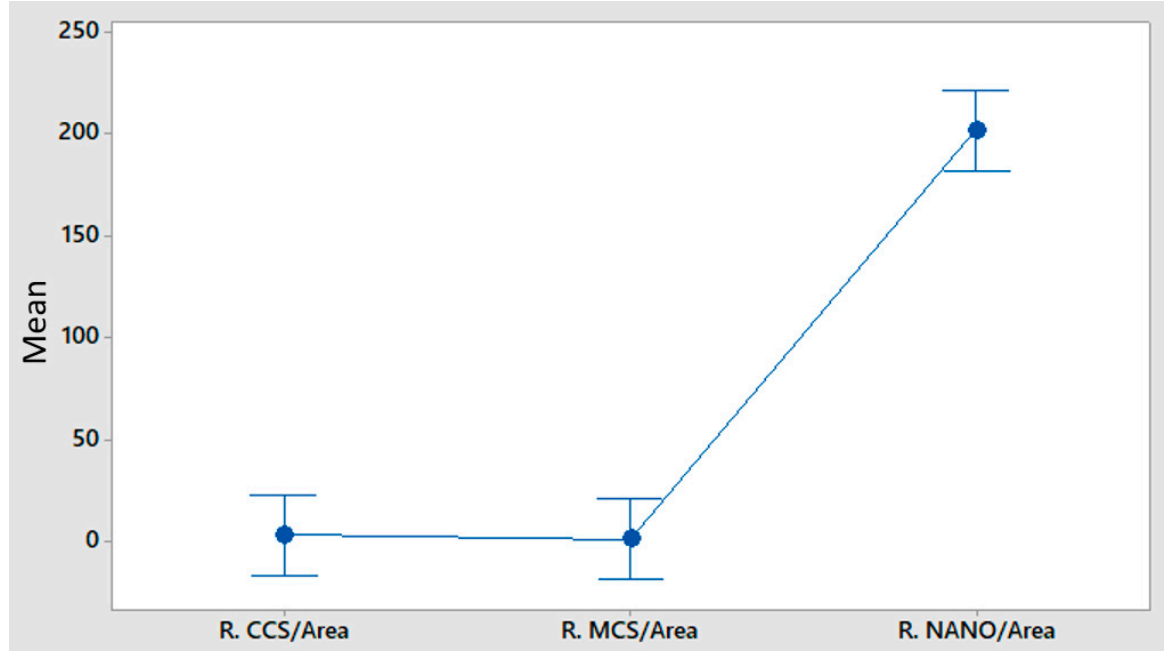

Figure 6. Interval Plot for the number of stores per type, per square kilometer ratio.

Next, we tested H4. It proposes that the pricing of CCS is usually targeted to medium SEL consumers, due to only having to compete with nanostores to a limited extent. Figure 7 presents an interval plot to compare the confidence intervals of the groups' means (ratio between CCS and each SEL), with a 95\% confidence interval for each group.

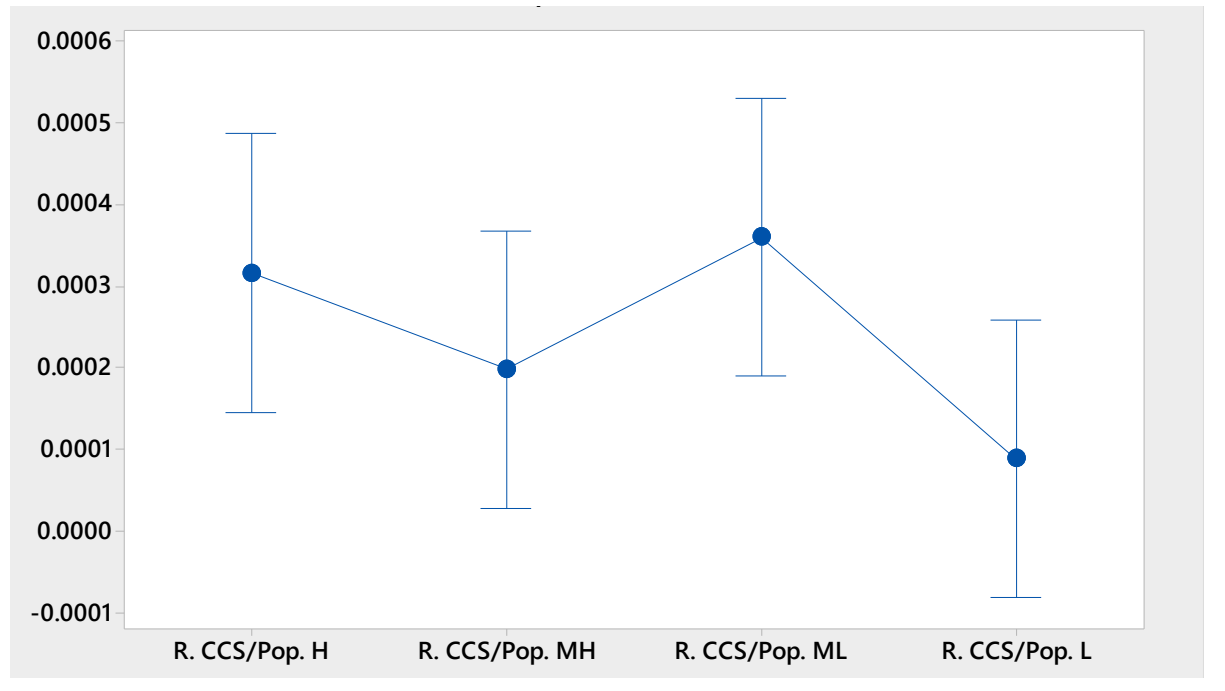

Figure 7. Interval Plot for CCS per SEL.

We can observe that the population means are statistically significant, suggesting that CCS are targeting all the SEL consumers by having a presence in areas of different SEL. The latter has been leveraged by online retailers like Amazon for product delivery (Xu et al. [21]) using CCS as locker kiosks.

In our dataset, we also found that CCS are usually opened in street corners (intersections) and main avenues of the city. Thus, the strategy of the CCS has been to cover more areas of the city, to have a greater presence, and to be located mainly in places with a high traffic influx and not within the local populations' neighborhoods.

Moreover, to test hypothesis 8 (H8), a Tukey multiple comparison test was conducted to determine which means, from the ratio of stores per population, differed from the rest. As depicted in Figure 8, all the means include zero, indicating that the differences are 
not statistically significant. Therefore, there is statistical evidence to conclude that H8 is reasonable. Nanostores, MCS, and CCS coexist under the conditions of a megacity in emerging markets like Mexico City, regardless of the socioeconomic populations that cohabit urban areas. Consequently, the statistical evidence suggests that H7 holds under the conditions of Mexico City.

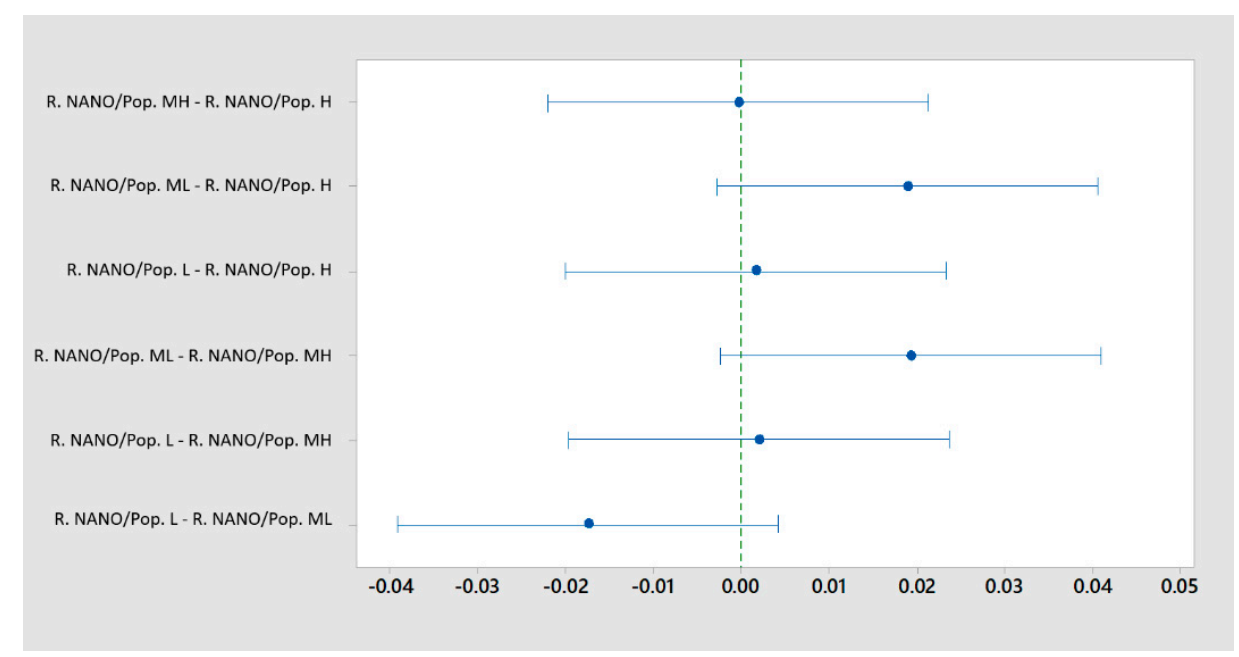

Figure 8. Tukey simultaneous test with 95\% confidence interval.

However, we can observe that the mean group differences are almost significantly different when the variable R. NANO/Pop. ML is included, implying that nanostores are more present in areas with medium-low socioeconomic levels. Statistically significant differences were returned when the same test was conducted with a $90 \%$ confidence interval; this outcome is associated with the results shown in Figure 4.

\section{Managerial Implications}

This research shows that nanostores, modern channel stores, and chain convenience stores coexist under megacity conditions in emerging markets like Mexico City, regardless of the socioeconomic populations that cohabit urban areas.

From the consumer's perspective, the coexistence of grocery retail stores means that they should identify the functional benefits offered by each channel and store format so that they can make financially wiser choices about when, and where, to buy groceries. Those choices can be influenced by word-of-mouth in offline or online settings. In the case of the latter, online reviews about a business increase customers' perceptions of the credibility of business, thus influencing customers' purchasing decisions (Anastasiei et al. [22]). This implies that nanostore shopkeepers should start building credibility in the virtual space.

If the customers' need is to buy-to-stock groceries, then they should select an MCS, such as a supermarket or hypermarket, where they may find a greater product assortment, lower prices for packaged goods, and more convenient, one-stop shopping.

In cases where customers do not have the purchasing power to visit a hypermarket or a membership store, then they could consider visiting hard discount stores. In our study, we identified that MCS have penetrated medium-low and low SEL areas by introducing small-size store formats like "Bodega Aurrerá Express", part of the Walmart group.

Concerning political aspects at a district level in highly congested areas, policymakers and urban planners should consider the impacts caused by the openings of new grocery stores. For example, in recent years, modern channel brands have developed new store formats to enter medium-low and low SEL neighborhoods in Mexico City. This strategy of proximity to the households reduces stores' distance from customers and customer traveling time. However, such stores usually lack parking spaces, forcing suppliers and customers to park on the sidewalk or engage in double parking. The latter leads to 
increased logistics costs as it introduces inefficiencies in the process of transporting goods via congestion. Furthermore, such parking space deficits may increase carbon emissions, noise, and other externalities.

On the other hand, if consumers' need is to buy-to-consume, then nanostores may be the most suitable channel providing customers do not need to pay via credit or debit cards. In that case, CCS could be the best choice given the availability of digital payment technology. Such stores usually offer wire transfer services and the payment of utilities to meet the customers' expectations and increase in-store traffic. A recent study shows that certain groups of consumers, such as "millennials", expect businesses to offer FinTech features such as peer-to-peer lending or money transfers (Dospinescu et al. [23]). For example, in the case of Mexico City, OXXO has launched a platform called "spin" to facilitate bank and money transfers among "spin" users.

The coexistence of MCS, CCS, and nanostores could be an opportunity for cooperative consumption-point programs. For instance, in Korea, retailers from various industries use a point-sharing policy to provide flexibility to consumers that may earn, and redeem, points at other stores that are part of the program (Moon et al. [24]).

For practitioners, the coexistence of the GR stores in a megacity implies that serving these multiple fulfillment channels drives higher growth in the market and competitiveness. These companies address the strategic challenge of effectively allocating their limited investment budgets into these sales channels, creating demand synergies across channels or cannibalization between them (Salmani et al. [25]).

To make informed decisions, practitioners should analyze the tradeoff between customers' preferences and the firm's costs by serving multiple channels. Moreover, our statistical evidence shows that the middle- and low-income consumers in emerging markets are attached to nanostores, as well as high- and medium-high-income groups. This outcome raises awareness among manufacturers and distributors about the need to implement vehicle routes to serve the small, coexisting MCS, CCS, and nanostores of densely populated areas using same fleet of vehicles to serve each channel, rather than sending separate vehicles to service each independently.

This strategy may avoid the unnecessary presence of freight vehicles working for the same company in city areas that do not have parking spaces, especially when serving nanostores.

For the nanostores' shopkeepers, coexistence means that they will not disappear as suggested by local news reports. Rather, coexistence implies that nanostores should modernize to some extent and continue competing in the grocery retail sector. Most nanostores depend on cash payments and very few use technologies to register transactions. Therefore, they share little information with manufacturers.

This result highlights the relevance of conducting a comprehensive study to identify the key factors that may enable nanostore shopkeepers' adoption, and use, of technology. Additionally, nanostores could take advantage of their proximity to households, as this is a convenience that consumers of various socioeconomic levels (SEL) prefer when acquiring "buy-to-consume" products, and one that facilitates the increased frequency of visits responsible for nanostores enduring.

\section{Conclusions and Further Research}

We conducted a comprehensive spatial and statistical analysis to gain a better understanding of the setting of the GR landscape in a developing megacity such as Mexico City. The statistical evidence observed in this study suggests that, regardless of the modernization of retail and the fast growth of CCS, nanostores will endure. Additionally, the three channels will continue to coexist, leading to a diverse and fragmented market.

Furthermore, our study shows statistical evidence suggesting that MCS are much more targeted to high and medium-high SEL areas, making the travel distance to low SEL populations more costly, and causing a slowdown in the diffusion of MCS among low SEL zones. Households of low SEL zones also share closer physical proximity to nanostores 
compared to MCS or CCS, thus facilitating the frequency of visits that they receive from consumers of these SEL groups.

The latter is one factor that makes nanostores endure despite the fast growth of modern retail. This implies that consumers will choose a store type because it meets their functional needs regardless of their SEL. For instance, during an economic crisis, consumers buy less but more frequently (McKenzie, D.J. [26]).

Our study also contributes to the literature by expanding the knowledge of the grocery retail sector in a megacity of a developing country. We also contribute by filling the gap in our knowledge regarding how the grocery retail landscape is configured in a megacity situated in a developing market, where customers from various socioeconomic levels cohabit.

Concerning future investigation, we recommend conducting further data analysis concerning the influence of transportation networks on the location of GR stores in Mexico City. Our spatial evidence shows that nanostores cover almost every street of the megacity while MCS and CCS generally locate their stores on avenues, on the corners of street intersections, and other main roads.

The insights provided by our work promotes distributor awareness of the need to implement a better fleet assignment to avoid the unnecessary presence of freight vehicles in certain city areas lacking parking spaces. They also motivate the understanding of the physical characteristics (i.e., morphology) that differentiate the grocery retail sector from other sectors, for example, the availability of parking spaces, trading hours, site location, and site election (e.g., street, corner, gas station or block), thus promoting informed decisions by businesses in this space.

Our results open avenues for future research. For example, how nanostores in Mexico City adapt operations, assortments, and prices; among other characteristics, once an MCS or CCS opens nearby. These characteristics are important, as they can increase the agility, adaptability, and alignment of nanostores to ensure that they remain competitive (Escamilla et al. [19]).

Additionally, researchers interested in this topic can conduct further research to determine the right assortment of products that MCS, CCS, and nanostores should offer to maximize profits while fulfilling customer needs. For example, a mathematical model can be used to classify inventory items, prioritizing those that increase profits while enhancing businesses' levels of service to their customers (Abdolazimi et al. [27]). Future studies on the grocery retail sector's triopoly (i.e., MCS, CCS, and nanostores) may take a game theory approach to identifying the best pricing strategies for each channel. For example, by basing commodity prices on consumer preferences and various store constraints, such as cash availability, inventory storage space, and product assortments, among others. A study using this approach could provide insights into how these channels may best develop collaborative mechanisms that improve firms' sustainability while adding value to the market, as suggested by previous studies in other sectors (Ray et al. [28]).

Concerning the limitations of the research, we have identified the following. First, our research considers the data of established businesses (i.e., formal). Thus, it does not include the informal nanostores (MCS and CCS are not considered informal). Second, our study does not consider the floating population, for instance, people living in the metropolitan or rural areas who travel to Mexico City to work or study. Third, we are not considering the fluctuation of nanostores (i.e., any changes in the number of stores due to openings and closures).

In addition, the knowledge gained from this study is limited to how the grocery retail landscape is configured in a developing megacity given the physical presence of the different channels therein. We did not consider the business performance of each channel's stores, nor was our study concerned with each channel's supply chain capabilities, which may increase their competitiveness and, thus, their presence in specific areas of the city. In this regard, we see opportunities for future research concerning the assessment of 
leanness and agility for each channel, as both principles improve supply chain efficiency (Mathiyazhagan et al. [29]).

Finally, the study covered in this work motivates the need for a categorization of stores that facilitates the decision-making process for policymakers and stakeholders of the grocery supply chain. Lastly, another avenue of research could aim to understand the effects of MCS, CCS, and nanostores closing. After the closure of a store, the sales will be redistributed not only among other stores of the same channel, but also among rival stores (Mayadunne et al. [30]). Therefore, understanding the impact of an event like the economic crisis from the COVID-19 pandemic could provide greater insight into the relationship between these channels and how they adapt to thrive under these conditions.

Author Contributions: Conceptualization, C.A.M.-Q., L.E.C.-B., J.C.V.-M. and K.M.G.-P.; Data curation, C.A.M.-Q.; Formal analysis, C.A.M.-Q., L.E.C.-B., J.C.V.-M. and K.M.G.-P.; Investigation, C.A.M.-Q., L.E.C.-B., J.C.V.-M. and K.M.G.-P.; Methodology, C.A.M.-Q., L.E.C.-B., J.C.V.-M. and K.M.G.-P.; Supervision, L.E.C.-B. and J.C.V.-M.; Validation, C.A.M.-Q. and L.E.C.-B.; Visualization, C.A.M.-Q. and K.M.G.-P.; Writing-original draft, C.A.M.-Q.; Writing-review \& editing, L.E.C.-B., J.C.V.-M. and K.M.G.-P. All authors have read and agreed to the published version of the manuscript.

Funding: This research received no external funding.

Institutional Review Board Statement: Not applicable.

Informed Consent Statement: Not applicable.

Data Availability Statement: Data available in a publicly accessible repository that does not issue DOIs. Publicly available datasets were analyzed in this study. This data can be found here: [https://www.inegi.org.mx/app/mapa/denue/default.aspx] (accessed on 18 September 2021) and [https://www.inegi.org.mx/datos/] (accessed on 18 September 2021).

Acknowledgments: The authors dedicate this article to the memory of Karla Gámez Pérez, a thoughtful and invaluable colleague. A beloved mother, wife, daughter, and dear friend left a lasting impact on our lives.

Conflicts of Interest: The authors declare no conflict of interest.

\section{References}

1. El Financiero. Las ‘Tienditas de la Esquina’ Podrían Desaparecer. 2016. Available online: https://www.elfinanciero.com.mx/ economia/las-tienditas-de-la-esquina-podrian-desaparecer/ (accessed on 14 April 2021).

2. El Sol de México. Las Tienditas de la Esquina, ¿Están en Vías de Extinción? 2016. Available online: https://www.elsoldemexico. com.mx/finanzas/Las-tienditas-de-la-esquina-\%C2\%BFest\%C3\%A1n-en-v\%C3\%ADas-de-extinci\%C3\%B3n-196066.html (accessed on 14 April 2021).

3. Forbes. Tienditas de la Esquina, en Riesgo de Desaparecer Por Supremacía de los Súpers. 2020. Available online: https: / / www.forbes.com.mx/negocios-tienditas-de-la-esquina-en-riesgo-de-desaparecer-por-supremacia-de-los-supers/ (accessed on 14 April 2021).

4. Alibeiki, H.; Li, S.; Vaidyanathan, R. Market dominance or product cost advantage: Retail power impacts on assortment decisions. Int. J. Prod. Econ. 2020, 222, 107505. [CrossRef]

5. Hervert-Escobar, L.; Esquivel-Flores, O.A.; Ramirez-Velarde, R.V. Optimal pricing model based on reduction dimension: A case of study for convenience stores. Procedia Comput. Sci. 2017, 108, 2079-2089. [CrossRef]

6. Fransoo, J.C.; Blanco, E.E.; Argueta, C.M. Reaching 50 Million Nanostores: Retail Distribution in Emerging Megacities; CreateSpace Independent Publishing Platform: Scotts Valley, CA, USA, 2017.

7. Blanco, E.; Fransoo, J. Reaching 50 Million Nanostores: Retail Distribution in Emerging Megacities; Technische Universiteit Eindhoven: Eindhoven, The Netherlands, 2013.

8. Ge, J.; Honhon, D.; Fransoo, J.C.; Zhao, L. Manufacturer competition in the nanostore retail channel. Eur. J. Oper. Res. 2020, 286, 360-374. [CrossRef]

9. Farhangmehr, M.; Marques, S.; Silva, J. Hypermarkets versus traditional retail stores—consumers' and retailers' perspectives in Braga: A case study. J. Retail. Consum. Serv. 2001, 8, 189-198. [CrossRef]

10. Goldman, A.; Hino, H. Supermarkets vs. traditional retail stores: Diagnosing the barriers to supermarkets' market share growth in an ethnic minority community. J. Retail. Consum. Serv. 2005, 12, 273-284. [CrossRef]

11. D'Andrea, G.; Lopez-Aleman, B.; Stengel, A. Why small retailers endure in Latin America. Int. J. Retail Distrib. Manag. 2006, 34, 661-673. [CrossRef] 
12. Coen, S.E.; Ross, N.A.; Turner, S. "Without tiendas it's a dead neighbourhood": The socio-economic importance of small trade stores in Cochabamba, Bolivia. Cities 2008, 25, 327-339. [CrossRef]

13. Lenartowicz, T.; Balasubramanian, S. Practices and performance of small retail stores in developing economies. J. Int. Mark. 2009, 17, 58-90. [CrossRef]

14. Paswan, A.; Pineda, M.D.L.D.S.; Ramirez, F.C.S. Small versus large retail stores in an emerging market-Mexico. J. Bus. Res. 2010, 63, 667-672. [CrossRef]

15. Amine, A.; Lazzaoui, N. Shoppers' reactions to modern food retailing systems in an emerging country. Int. J. Retail Distrib. Manag. 2011, 39, 562-581. [CrossRef]

16. Narayan, V.; Rao, V.R.; Sudhir, K. Early adoption of modern grocery retail in an emerging market: Evidence from India. Mark. Sci. 2015, 34, 825-842. [CrossRef]

17. Boulaksil, Y.; Belkora, M.J. Distribution strategies toward nanostores in emerging markets: The Valencia case. Interfaces 2017, 47, 505-517. [CrossRef]

18. Boulaksil, Y.; Fransoo, J.C.; Blanco, E.E.; Koubida, S. Understanding the fragmented demand for transportation-Small traditional retailers in emerging markets. Transp. Res. Part A Policy Pract. 2019, 130, 65-81. [CrossRef]

19. Escamilla, R.; Fransoo, J.C.; Tang, C.S. Improving agility, adaptability, alignment, accessibility, and affordability in nanostore supply chains. Prod. Oper. Manag. 2021, 30, 676-688. [CrossRef]

20. Goswami, M.; De, A.; Habibi, M.K.K.; Daultani, Y. Examining freight performance of third-party logistics providers within the automotive industry in India: An environmental sustainability perspective. Int. J. Prod. Res. 2020, 58, 7565-7592. [CrossRef]

21. Xu, X.; Shen, Y.; Chen, W.A.; Gong, Y.; Wang, H. Data-driven decision and analytics of collection and delivery point location problems for online retailers. Omega 2020, 100, 102280. [CrossRef]

22. Anastasiei, B.; Dospinescu, N.; Dospinescu, O. Understanding the Adoption of Incentivized Word-of-Mouth in the Online Environment. J. Theor. Appl. Electron. Commer. Res. 2021, 16, 56. [CrossRef]

23. Dospinescu, O.; Dospinescu, N.; Agheorghiesei, D.-T. FinTech Services and Factors Determining the Expected Benefits of Users: Evidence in Romania for Millennials and Generation Z. EM Econ. Manag. 2021, 24, 101-118.

24. Moon, I.; Xu, J.; Feng, X.; Ruan, X. Cooperative sales promotion with a point-sharing policy: Advantages and limitations. Omega 2020, 94, 102038. [CrossRef]

25. Salmani, Y.; Partovi, F.Y; Banerjee, A. Customer-driven investment decisions in existing multiple sales channels: A downstream supply chain analysis. Int. J. Prod. Econ. 2018, 204, 44-58. [CrossRef]

26. McKenzie, D.J. The consumer response to the Mexican peso crisis. Econ. Dev. Cult. Chang. 2006, 55, 139-172. [CrossRef]

27. Abdolazimi, O.; Shishebori, D.; Goodarzian, F.; Ghasemi, P.; Appolloni, A. Designing a new mathematical model based on ABC analysis for inventory control problem: A real case study. RAIRO-Oper. Res. 2021, 55, 2309-2335. [CrossRef]

28. Ray, A.; De, A.; Mondal, S.; Wang, J. Selection of best buyback strategy for original equipment manufacturer and independent remanufacturer-game theoretic approach. Int. J. Prod. Res. 2020, 59, 1-30. [CrossRef]

29. Mathiyazhagan, K.; Agarwal, V.; Appolloni, A.; Saikouk, T.; Gnanavelbabu, A. Integrating lean and agile practices for achieving global sustainability goals in Indian manufacturing industries. Technol. Forecast. Soc. Chang. 2021, 171, 120982. [CrossRef]

30. Mayadunne, S.; Johar, M.; Saydam, C. Competitive store closing during an economic downturn. Int. J. Prod. Econ. 2018, 199, 162-178. [CrossRef] 